\title{
Efficacy of morning-only compared with split-dose polyethylene glycol electrolyte solution for afternoon colonoscopy: a randomized controlled single-blind study.
}

\author{
Rebecca Matro, MD \\ Thomas Jefferson University \\ Anastasia Shnitser, MD \\ Thomas Jefferson University \\ Maya Spodik, MD \\ Thomas Jefferson University \\ Follow this and additional works at: https://jdc.jefferson.edu/internalfp \\ fnnstantine Daskalakis, Sc.D

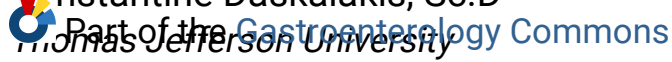 \\ Let us, know how access to this document benefits you
}

Thomas Jefterson University

\section{Recommended Citation}

Matro, MD, Rebecca; Shnitser, MD, Anastasia; Spodik, MD, Maya; Daskalakis, Sc.D, Constantine;

Katz, MD, Leo; Murtha, BA, Alexandra; and Kastenberg, MD, David, "Efficacy of morning-only

compared with split-dose polyethylene glycol electrolyte solution for afternoon colonoscopy: a

randomized controlled single-blind study." (2010). Division of Internal Medicine Faculty Papers \&

Presentations. Paper 3.

https://jdc.jefferson.edu/internalfp/3

This Article is brought to you for free and open access by the Jefferson Digital Commons. The Jefferson Digital Commons is a service of Thomas Jefferson University's Center for Teaching and Learning (CTL). The Commons is a showcase for Jefferson books and journals, peer-reviewed scholarly publications, unique historical collections from the University archives, and teaching tools. The Jefferson Digital Commons allows researchers and interested readers anywhere in the world to learn about and keep up to date with Jefferson scholarship. This article has been accepted for inclusion in Division of Internal Medicine Faculty Papers \& Presentations by an authorized administrator of the Jefferson Digital Commons. For more information, please contact: JeffersonDigitalCommons@jefferson.edu. 


\section{Authors}

Rebecca Matro, MD; Anastasia Shnitser, MD; Maya Spodik, MD; Constantine Daskalakis, Sc.D; Leo Katz, MD; Alexandra Murtha, BA; and David Kastenberg, MD 
As submitted to:

\title{
American Journal of Gastroenterology
}

\author{
And later published as:
}

\begin{abstract}
"Efficacy of morning-only compared with split-dose polyethylene glycol electrolyte solution for afternoon colonoscopy: A randomized controlled single-blind study"
\end{abstract}

\section{Volume 105, Issue 9, September 2010, Pages 1954- 1961}

\section{DOI: DOI: 10.1038/ajg.2010.160}

Short title: Morning-only vs split dose PEG-ELS for afternoon colonoscopy

Authors: Rebecca Matro, M.D., ${ }^{1}$ Anastasia Shnitser, M.D., ${ }^{1}$ Maya Spodik, M.D., ${ }^{2}$

Constantine Daskalakis, Sc.D, ${ }^{3}$ Leo Katz, M.D., ${ }^{2,4}$ Alexandra Murtha, B.A., ${ }^{2}$ David Kastenberg, M.D. ${ }^{2,4}$

Affiliations: 1. Department of Internal Medicine, Thomas Jefferson University, Philadelphia, PA; 2. Division of Gastroenterology and Hepatology, Thomas Jefferson University, Philadelphia, PA; 3. Department of Biostatistics, Thomas Jefferson University, Philadelphia, PA; 4. Jefferson Medical College, Thomas Jefferson University, Philadelphia, PA

Corresponding Author: David Kastenberg, M.D., 480 Main Building, 132 S. 10th Street, Philadelphia, PA 19107. 215-955-8900; David.Kastenberg@jefferson.edu 


\title{
Efficacy of morning-only compared to split dose polyethylene glycol-electrolyte solution (PEG-ELS) for afternoon colonoscopy: A randomized controlled single- blind study
}

Rebecca Matro, M.D., Anastasia Shnitser, M.D., Maya Spodik, M.D., Constantine Daskalakis, Sc.D, Leo Katz, M.D., Alexandra Murtha, B.A., David Kastenberg, M.D.

\begin{abstract}
Objectives: Administering a purgative close to the time of colonoscopy is optimal for cleansing. The aim of this study was to compare the efficacy and tolerability of AM-only PEG-ELS to split dose (PM/AM) PEG-ELS for afternoon colonoscopy.
\end{abstract}

Methods: Single center, prospective, randomized, investigator-blinded, non-inferiority study comparing AM-only to PM/AM PEG-ELS for afternoon outpatient colonoscopy. The primary endpoint was whole colon prep adequacy. Tolerance and polyp detection were secondary outcomes.

Results: 125 patients were randomized and 9 withdrew without taking any prep. Of 116 analyzed, 62 received AM-only prep and 54 received PM/AM prep. The whole colon prep was adequate in $92 \%$ in the AM-only group versus $94 \%$ in the PM/AM group (95\% lower confidence limit, LCL, for the difference $=-11.3 \%$, non-inferiority $\mathrm{p}=0.013$ ), while the right colon prep was adequate in $93 \%$ and $92 \%$, respectively $(95 \% \mathrm{LCL}=-7.8 \%$, non-inferiority $\mathrm{p}=0.003$ ). Polyp detection was greater, and not inferior, in the AM-only group $($ mean $=1.57$ versus 0.94 polyps/patient, non-inferiority $\mathrm{p}=0.007$ ). The overall incidence of adverse events was not significantly different between the two groups $(\mathrm{p}=0.273)$, but the AM-only group had lower incidence of abdominal pain $(\mathrm{p}=0.024)$. The AM-only group also had better sleep quality $(\mathrm{p}=0.007)$ and less interference with the prior work day $(\mathrm{p}=0.019)$.

Conclusion: AM-only and PM/AM PEG-ELS are clinically equivalent with respect to cleansing efficacy and polyp detection. AM-only prep was associated with a lower incidence of abdominal pain, superior sleep quality, and less interference with work day prior to colonoscopy. 


\section{Introduction}

Recently supported in a position paper by the American College of

Gastroenterology, superior colon cleansing is more likely if at least some of a purgative is ingested on the day of colonoscopy (1). Day-of-colon dosing can be achieved through two strategies - split (PM/AM) dosing where part of the purgative is administered the night prior to colonoscopy and the remainder within $\sim 6$ hours of the procedure, and morning-only (AM-only) dosing where the entire prep is taken on the day of colonoscopy (2-5). By linking the final dose of purgative to the timing of colonoscopy, a greater chance of adequate cleansing is assured regardless of the time of colonoscopy.

There may be some distinct advantages to employing an AM-only dosing schedule in which colonoscopy, the prep and procedure, becomes a 1-day process. For one, it has the potential to minimize the prep's interference on the patient's ability to work and function the day prior. Also, the impact on sleep may be diminished if no prep is consumed in the evening. Additionally, patients may perceive AM-only dosing as better tolerated since the predictable adverse events occur "once" on the day of procedure as compared to over two days. Finally, this dosing regimen extends utilization of the endoscopy lab well into the afternoon (3).

However, the potential disadvantages to AM-only dosing bear consideration. For some patients, such a regimen may not be practical for early morning procedures depending on the start time of the prep. Second, sodium phosphate cannot be utilized given the potential risk of administering a large dose over a short interval $(6,7)$. Finally, though proven to be effective for AM-only dosing, 4L polyethylene glycol-electrolyte solution (PEG-ELS) administered all in the morning might be poorly tolerated (8). 
Utilizing a 2L PEG-ELS solution which does not require supplemental laxatives and is already FDA-approved for single (PM-only) and split dosing (PM/AM), we evaluated the efficacy, tolerance, and quality of life measures of AM-only dosing for afternoon colonoscopy. We hypothesized that AM-only 2L PEG-ELS is as effective as $\mathrm{PM} / \mathrm{AM}$ dosing for achieving adequate cleansing and detecting polyps, and furthermore that this administration schedule improves quality of life by interfering less with the day prior to colonoscopy.

\section{Methods}

This was a prospective, randomized, investigator-blinded study, comparing AMonly to PM/AM PEG-ELS dosing for patients undergoing afternoon colonoscopy. All patients provided written informed consent. The study was conducted at a single site in Philadelphia, PA, and was approved by the institution's IRB. It was registered at ClinicalTrials.gov (http://www.clinicaltrials.gov), with identifier NCT00929916. Subjects

Patients 18 years of age or older, scheduled to undergo elective outpatient afternoon (12 pm or later) colonoscopy at a university hospital were eligible to participate. Exclusion criteria included pregnancy, breast feeding, known or suspected gastroparesis, chronic nausea or vomiting, bowel obstruction, hypomotility syndrome (pseudo-obstruction, megacolon, etc.), severe constipation $(\leq 1$ bowel movement a week), greater than $50 \%$ colon resection, known glucose-6-phospate dehydrogenase deficiency, PEG allergy, significant psychiatric illness, or inability to provide informed consent. 
Study design: Randomization and Protocol

Using a randomization schedule generated by the website Randomization.com (http://www.randomization.com), eligible patients were assigned to AM-only or PM/AM PEG-ELS by an investigator not involved in the colonoscopy procedure. A commercially available 2L PEG-ELS containing sodium sulfate, sodium ascorbate, and ascorbic acid (MoviPrep®, Salix Pharmaceuticals, Morrisville, NC) was used. Subjects were provided with a standard PEG-ELS kit and given detailed instructions regarding preparation of the PEG-ELS, the administration of their assigned schedule, and routine preparation for colonoscopy including diet, hydration, and when to begin fasting. The patient's endoscopist was not involved in the randomization process and remained blinded to the patient's preparation schedule for the duration of the study. All study procedures were performed by an attending physician; fellows did not participate.

Subjects assigned to AM-only administration took the first $1 \mathrm{~L}$ dose seven hours before colonoscopy and the second $1 \mathrm{~L}$ four hours before colonoscopy. Subjects randomized to PM/AM dose PEG-ELS were instructed to take the first liter (250 cc every 15 minutes) plus $500 \mathrm{cc}$ of clear liquids at $6 \mathrm{pm}$ the night prior to colonoscopy, and the second liter four hours before colonoscopy.

Diet instructions were identical for both study groups. On the day prior to colonoscopy, patients were permitted a low residue breakfast (before $10 \mathrm{am}$ ). Patients received instructions regarding a low residue diet, including a list of acceptable and unacceptable foods (Appendix A). After 10 am on the day prior to colonoscopy, patients were allowed clear liquids until 2.5 hours before colonoscopy at which point they took nothing further by mouth except for medications with sips of water. 
All subjects were called by an investigator who was not performing the colonoscopy within 1 week of their scheduled procedure and reminded about their colonoscopy appointment and specific preparation. On the day of their afternoon colonoscopy, patients arrived one hour prior to their scheduled procedure and met with an investigator who was not performing the colonoscopy. Patients completed several questionnaires evaluating compliance, tolerance, satisfaction, sleep, and work and productivity for the previous day. Tolerance was measured using a 10-point Likert scale, and patients rated side effects (nausea, vomiting, abdominal pain, lightheadedness, bloating) from 0 (none) to 10 (severe). Sleep quantity was measured by comparing the average number of hours the patient normally sleeps to the number of hours they slept the night prior to colonoscopy. Sleep quality was rated on a 5-point scale: very poor, poor, average, good, very good. Finally, work and productivity were measured using questions adapted from The Health and Labour Questionnaire (9). Patients rated how much their work, daily activities, and overall productivity were impaired by the preparation. Patients who went to work the day prior responded with strongly agree, agree, disagree, or strongly disagree to statements focused on whether they had trouble concentrating, had to work alone, could not do some work, or needed co-workers to do some work. Patients who did not have work the day before colonoscopy rated how much the preparation affected their household work, shopping and errands, child care, and other chores. A physician or registered nurse performed a safety assessment that included vital signs and physical exam. All patients got monitored anesthesia care (MAC) with propofol-based sedation administered by a certified registered nurse anesthetist. 
During the procedure, an investigator assisted the endoscopist in recording total procedure and withdrawal time (excluding interventions), cecal intubation, findings, and specific information regarding polyps, including the number, location, size, morphology, and method of excision. At the conclusion of the procedure, the endoscopist graded the quality of preparation for the whole colon and the right colon (excellent, good, fair, or poor) and estimated the amount of flushing required (none, $<50 \mathrm{cc}, 50-100 \mathrm{cc}$, or $>100$ cc). A descriptor of each preparation grade was available for the endoscopist to review at the time of assigning the grade (Appendix B). When final pathology reports became available for each patient, an investigator not involved in performing the colonoscopy recorded the following for each polyp: pathologic size, histology (hyperplastic, adenomatous, cancer, other), and additional histologic features for adenomas including grade of dysplasia (low grade, high grade) and the presence of a villous or serrated component.

Masking

To ensure blinding, patients were instructed by an investigator not to discuss their preparation assignment with the endoscopist. In addition, all preparation instructions were given in a closed exam room without the endoscopist present. At the time of colonoscopy, the endoscopists documented whether they had remained blind to the patients' preparation through completion of the colonoscopy and grading of the prep.

\section{Outcome measures}

The primary trial endpoint was the dichotomous index of prep quality (adequate versus inadequate) for the whole colon. Adequate was defined as a good or excellent prep, and inadequate was defined as a fair or poor prep. The adequacy of cleansing for 
the right colon and the need for flush were secondary endpoints of prep quality.

Additional secondary endpoints included prep completion, side effects (nausea, vomiting, abdominal pain, bloating, light-headedness), measures of quality of life (overall satisfaction, sleep quality, interference with work and overall productivity), and colonoscopy findings.

\section{Statistical analysis}

The analyses of the endpoints of prep quality and findings evaluated noninferiority of the AM-only prep compared to the PM/AM prep, with pre-specified margins. For prep quality, we expected about $90 \%$ of the cases in the PM/AM prep to be judged adequate, and the non-inferiority margin was set at $-15 \%$ (i.e., the adequacy rate of the AM-only prep should not be lower than that of the PM/AM prep by more than $15 \%$ ). The study was designed to have $82 \%$ power to establish non-inferiority (using a one-sided test with alpha 0.05 and a target sample size of 110). The assumptions and prespecified non-inferiority margins for flush and the colonoscopy findings endpoints are summarized in Table 1. For each endpoint, we computed differences between the two groups, along with a one-sided $95 \%$ confidence interval and a one-sided p-value against the non-inferiority margin (with a significant p-value establishing non-inferiority). For the dichotomous endpoints, exact procedures were used.

The analyses of the side effects and measures of quality of life tested superiority of the AM-only prep compared to the PM/AM prep. Fisher's exact test was used for categorical variables, and t-test or the non-parametric Kruskall-Wallis test was used for continuous variables (all tests were two-sided, with alpha 0.05 , with significant p-values establishing a difference between the two groups). All subjects were included in the 
group that they were assigned to, irrespective of whether (or when) they took their preparation doses. However, subjects who cancelled their colonoscopy after randomization did not provide any data and consequently were excluded from all analyses. The analyses were carried out in SAS 9.2 (SAS Institute Inc., Cary, NC) and StatXact 8 (Cytel Inc, Cambridge, MA).

\section{Results}

Participant flow and follow-up

From October 2008 through April 2009, 125 patients referred for outpatient colonoscopy were initially randomized to AM-only or PM/AM prep (See Figure 1 Flow Diagram). However, 9 patients withdrew prior to taking any prep (5 patients cancelled their procedures and were unable to reschedule within the study time period, 1 patient required a morning procedure because of co-morbid conditions, 1 patient preferred a morning procedure, and 2 patients did not want to continue participating in the study), and therefore the analyses included 116 patients, of whom 62 received AM-only prep and 54 received $\mathrm{PM} / \mathrm{AM}$ prep. One patient in the AM-only group experienced nausea/vomiting and did not undergo colonoscopy but was included in the analyses of side effects and quality of life. The 115 procedures were performed by two endoscopists (with 110 of them performed by the study's principal investigator, D.K.). Endoscopist masking was maintained for all but one case. Table 2 summarizes the characteristics of the study patients. Compared to PM/AM prep, the AM-only group had a somewhat greater number of women, and relatively fewer patients with a history of GERD and use of acid suppression medications, as well as cardiovascular disease (CVD). 


\section{Prep Quality}

Prep quality was measured for the 115 patients who underwent colonoscopy and is summarized in Table 3. The colonoscopy was completed in all but one patient in the AM-only group whose procedure was aborted because of poor prep. The whole colon prep was adequate for 56/61 (91.8\%) patients in the AM-only group versus 51/54 (94.4\%) patients in the PM/AM group (95\% lower confidence limit, LCL, for the difference $=-11.3 \%$, non-inferiority $\mathrm{p}=0.013$ ). The right colon prep was adequate for $56 / 61(93.3 \%)$ patients in the AM-only group versus 49/54 (92.5\%) patients in the PM/AM group $(95 \% \mathrm{LCL}=-7.8 \%$, non-inferiority $\mathrm{p}=0.003)$. Withdrawal time, which consisted of the time spent inspecting the mucosa and excluded time for interventions, ranged from 3.8 to 24 minutes, with medians of 8.0 minutes in the AM-only group versus 7.3 minutes in the PM/AM group $(\mathrm{p}=0.637)$. Total procedure time, excluding time for interventions, ranged from 5.5 to 39 minutes, with medians of 12.8 versus 12.4 minutes, respectively $(\mathrm{p}=0.147)$. The need for any flushing during the colonoscopy was similar between the study groups $(26 / 61,43 \%$, in the AM-only group versus $28 / 54,52 \%$, in the $\mathrm{PM} / \mathrm{AM}$ group, $95 \%$ upper confidence limit, UCL, for the difference $=6.4 \%$, noninferiority $\mathrm{p}=0.001$, Table 3 ).

Prep completion, side effects, and quality of life

Table 4 summarizes prep completion, side effects, and measures of quality of life. Over $90 \%$ of both prep doses was taken by $84 \%$ (52/62) in the AM-only group versus $72 \%(39 / 54)$ in the PM/AM group (95\% confidence interval, CI, for the difference: $-3.7 \%$ to $27.3 \%, p=0.073$ ). The overall incidence of side effects was not significantly different between the two groups, although abdominal pain $(12 / 62,19 \%$, versus $21 / 54,39 \%$; $95 \%$ 
CI: $-35.6 \%$ to $-2.2 \%, \mathrm{p}=0.024)$ and light-headedness $(18 / 62,29 \%$, versus $24 / 54,46 \%$, 95\% CI: $-34.9 \%$ to $0.9 \%, p=0.082$ ) appeared less common in the AM-only group (Table 4). After controlling for age, sex, history of cardiovascular disease, and use of acid suppression medications via logistic regression, the two groups remained different for the incidence of abdominal pain but not for light-headedness (adjusted $\mathrm{p}=0.045$ and 0.152 , respectively). However, the severity of abdominal pain between the two groups was not significantly different $(\mathrm{p}=0.144)$. One patient in the AM-only group who was severely obese $\left(\mathrm{BMI}=40 \mathrm{~kg} / \mathrm{m}^{2}\right)$ aspirated during the procedure, was observed in the hospital for 24 hours, and treated with one week of oral antibiotics.

Duration of sleep the night prior to colonoscopy was not significantly different between the two groups ( $\mathrm{p}=0.675$, Table 4$)$, but the AM-only group had significantly better sleep quality ( $p=0.007$, Table 4$)$. About a fifth of the patients in the AM-only group rated their sleep as "very good," while this was the case for only a single patient in the PM/AM group. The proportion of patients that slept at least $80 \%$ of their typical hours was not significantly different between the groups $(\mathrm{p}=0.675$, Table 4$)$.

In the subset of patients who went to work the day prior to colonoscopy, the AMonly group reported less interference with their ability to work $(p=0.019$, Table 4$)$. Overall satisfaction and the prep's interference with overall productivity in everyday life were not significantly different between the two groups $(p=0.975$ and 0.687 , respectively, Table 4). The majority of patients favored repeating the same preparation in the future $(51 / 62,82 \%$, in the AM-only group versus $43 / 54,80 \%$, in the PM/AM group, $\mathrm{p}$ $=0.814$ ), and most maintained this preference even when the alternative prep schedule 
was explained and offered as an option $(46 / 62,74 \%$, in the AM-only group versus $37 / 54$, $69 \%$, in the PM/AM group, $\mathrm{p}=0.541)$.

\section{Colonoscopy findings}

Table 5 summarizes polyp and adenoma/cancer detection. The average number of polyps per patient was 0.67 higher in the AM-only group (mean = 1.57 in AM-only versus 0.94 in PM/AM, 95\% LCL for difference $=0.04$, non-inferiority $\mathrm{p}=0.007$ ).

Positive pathology findings included "low-risk" adenomas (low-grade dysplasia or serrated histology with size $<1 \mathrm{~cm}$ ), "high-risk" adenomas (high-grade dysplasia, villous histology, or size $\geq 1 \mathrm{~cm}$ ), or cancer. Compared to the PM/AM group, the AM-only group had an average of 0.24 more findings per patient (mean $=0.70$ in AM-only versus 0.46 in $\mathrm{PM} / \mathrm{AM}, 95 \% \mathrm{LCL}$ for difference $=-0.12$, non-inferiority $\mathrm{p}=0.047$ ) and a greater detection rate for findings $(22 / 60,37 \%$, versus $14 / 54,26 \%, 95 \%$ LCL for difference $=-$ 3.9, non-inferiority $\mathrm{p}=0.038$ ). The AM-only group also had a somewhat higher detection rate with respect to high-risk adenomas or cancer than the PM/AM group (8/60, 13\%, versus $6 / 54,11 \%$ ), but the study precision was not sufficient to establish non-inferiority on such findings $(95 \% \mathrm{LCL}=-8.7$, non-inferiority $\mathrm{p}=0.282)$.

\section{Discussion}

An ideal colon purgative is safe, effective, and well tolerated. Despite more than 14 million colonoscopies being performed each year, the historic rates for adequate cleansing are unacceptably low and range from 70-82\% (10-13). Recent studies have shown that ingesting at least part of the purgative on the day of colonoscopy and coordinating the final dose of purgative with the start time of colonoscopy is more likely 
to result in adequate colon cleansing (2-5). Generally, this is accomplished by splitting the purgative between the evening prior and the morning of colonoscopy. This study expands the options for patients by demonstrating that ingestion of low volume PEG-ELS prep entirely on the day of colonoscopy is as good as a split dose schedule.

Purgative ingestion entirely on the day of colonoscopy successfully met the predefined quality endpoints, as compared to traditional split dosing. First and foremost, the rate of adequate cleansing for the whole colon was similarly high in the two groups (92\% in the AM-only group and $94 \%$ in the PM/AM group). Adequate cleansing of the right colon, typically more difficult, was also similar and very high in both study arms (93\% versus $92 \%$, respectively). This rate of success, much higher than seen in retrospective studies often employing a long interval between prep and procedure, also affirms the importance of dosing the prep close to the time of colonoscopy (10-13). A non-inferiority design with respect to the primary endpoint of cleansing was utilized because split dosing typically produces a high level of adequate bowel preparation. Importantly, the trial results excluded big deficiencies in quality of the morning-only prep compared to the traditional split dosing. However, even though the study established non-inferiority using a margin of $-15 \%$, it is possible that the PM/AM prep may have somewhat better quality (although probably not by more than 10 percentage points or so). A further measure of colon cleanliness, the need for flushing, was also not inferior in the AM-only group (and in fact appeared somewhat better), compared to the PM/AM group. Finally, polyp detection and pathology findings (any adenoma or cancer) in the AM-only group were not less common than the PM/AM group (and the former even appeared more sensitive than the latter). The confidence intervals for these endpoints excluded any large 
differences in favor of the PM/AM prep. For the specific finding of high-risk adenomas or cancer, the AM-only group appeared slightly more sensitive than the PM/AM group, but the study failed to establish non-inferiority. This is probably due to a type II error as the study was underpowered to establish non-inferiority on an endpoint with such low event rate.

Results on several adverse events and quality of life measures were mixed. Abdominal pain occurred significantly less often with AM-only dosing. The study failed to establish superiority of the AM-only dosing on other side effects, although some of those were somewhat less common in the AM-only group. The AM-only prep had better quality of sleep, but there was no difference between the two preps in duration of sleep. Perhaps apparent benefit on sleep quality was negated by the need to arise early in the AM-only group. For instance, a 12 pm (earliest start time) colonoscopy required the prep begin at 5 am for the AM-only group and 8 am for the PM/AM group.

With respect to work, of patients who worked outside the home, only $56 \%$ in the PM/AM group and 64\% in the AM-only group actually went to work the day before colonoscopy. Theoretically, PM/AM dosing should have little impact on the workday, and AM-only dosing none. All patients were permitted a low residue breakfast up to 10 am, and then clear liquids up to 2.5 hours before the colonoscopy, but this restriction may have been enough to impact the work day. Among those who did go to work, patients in the AM-only group reported significantly less interference in the workday. The vast majority of patients in both groups found little to no impact of the preparation on overall productivity. Satisfaction was high for both groups and did not vary significantly between the two prep regimens. 
Several factors, in addition to dosing the purgative close to the time of colonoscopy, may have contributed to a high rate of adequacy for both groups. First, low volume PEG-ELS is better tolerated than four liter PEG purgatives, and likely leads to greater compliance $(14,15)$. In addition, patients were carefully educated and supported throughout the pre-colonoscopy period. This has been shown to boost the success rate of colon preparation (16). The investigator consenting the patient provided detailed instructions on diet, purgative preparation and administration, and the possible side effects that might be experienced. With respect to diet, this was not highly restrictive as we chose a diet consisting of a low residue breakfast before $10 \mathrm{am}$ on the day prior followed by clears up to 2.5 hours before colonoscopy. Though many physicians order a clear liquid diet for 24 hours, several studies support a less restrictive diet $(4,17,18)$.

A member of the research team uninvolved in grading the preparation called patients within one week of their scheduled procedure to remind them about their procedure, review their specific prep, and provide a contact number for patients to call for prep-related questions. Most patients undergoing routine colonoscopy do not have this degree of attention and support.

Another consideration is that all but five colonoscopies were performed by one of the two endoscopists involved in this study. Though this should not have affected the non-inferiority results as the endoscopists were blinded to prep, if the predominant grader was "lenient" then colon grades could have all been inflated and resulted in overall high adequacy rates. Finally, these data likely only apply to patients undergoing afternoon colonoscopy. 
One patient in the AM-only group aspirated while under moderate sedation and developed aspiration pneumonia. Both groups of patients in the study presented herein were asked to complete the second dose of PEG-ELS 4 hours before their scheduled procedure time. Aspiration, though rare, is serious and has not been reported in several studies that have specifically evaluated PEG-ELS dosing on the day of colonoscopy (25,8). Large published series of patients receiving propofol-based anesthesia for endoscopy have found aspiration to be a rare event. In one, of 2,000 healthy patients undergoing endoscopic procedures with nurse-administered propofol, there were five patients whose oxygen saturation fell to below $85 \%$ (19). Several conditions may be associated with increased incidence of pulmonary aspiration during general anesthesia, including extremes of age, male gender, pregnancy, difficult airway management, and factors that decrease gastric emptying, such as concurrent opioid administration, gastrointestinal obstruction or dysfunction, obesity, or depressed level of consciousness $(20,21)$. Our patient who aspirated had no obvious risk factors for aspiration other than a BMI of $40 \mathrm{~kg} / \mathrm{m}^{2}$, classifying her as morbidly obese. In patients who are high risk for aspiration, measures such as increasing the interval between the second purgative dose and the time of colonoscopy and/or reducing the prep volume consumed the day of colonoscopy may be prudent.

In conclusion, our study showed that AM-only and PM/AM administration strategies for PEG-ELS are clinically equivalent with respect to cleansing efficacy, need for flushing, polyp detection, and adenoma or cancer detection. Furthermore, AM-only dosing was superior to PM/AM dosing with respect to some quality of life measures, as well as the incidence of prep-associated abdominal pain. These results support the notion 
that timing the last dose of purgative relative to the start time of colonoscopy results in a high rate of adequate colon cleansing, regardless of whether the prep is started the night prior or on the morning of colonoscopy. AM-only dosing is a viable option that moves the process of colonoscopy - prep and procedure - toward becoming a one-day procedure. While the paradigm has been for colonoscopy to be performed in the morning, linking the administration of the prep to the time of the procedure for both AM-only and PM/AM dosing may make late morning and afternoon colonoscopy equally or more attractive to patients in the future.

Acknowledgments: We wish to thank Kathleen Hilbert, RN, for her significant assistance with patient consents and data collection during procedures, and Cynthia Miller, RN, for research assistance and for creating the study database. We would also like to acknowledge Emily Rubin, RD, for creating the list of low-residue diet foods. 
Figure 1. Patient assignment and disposition flow diagram

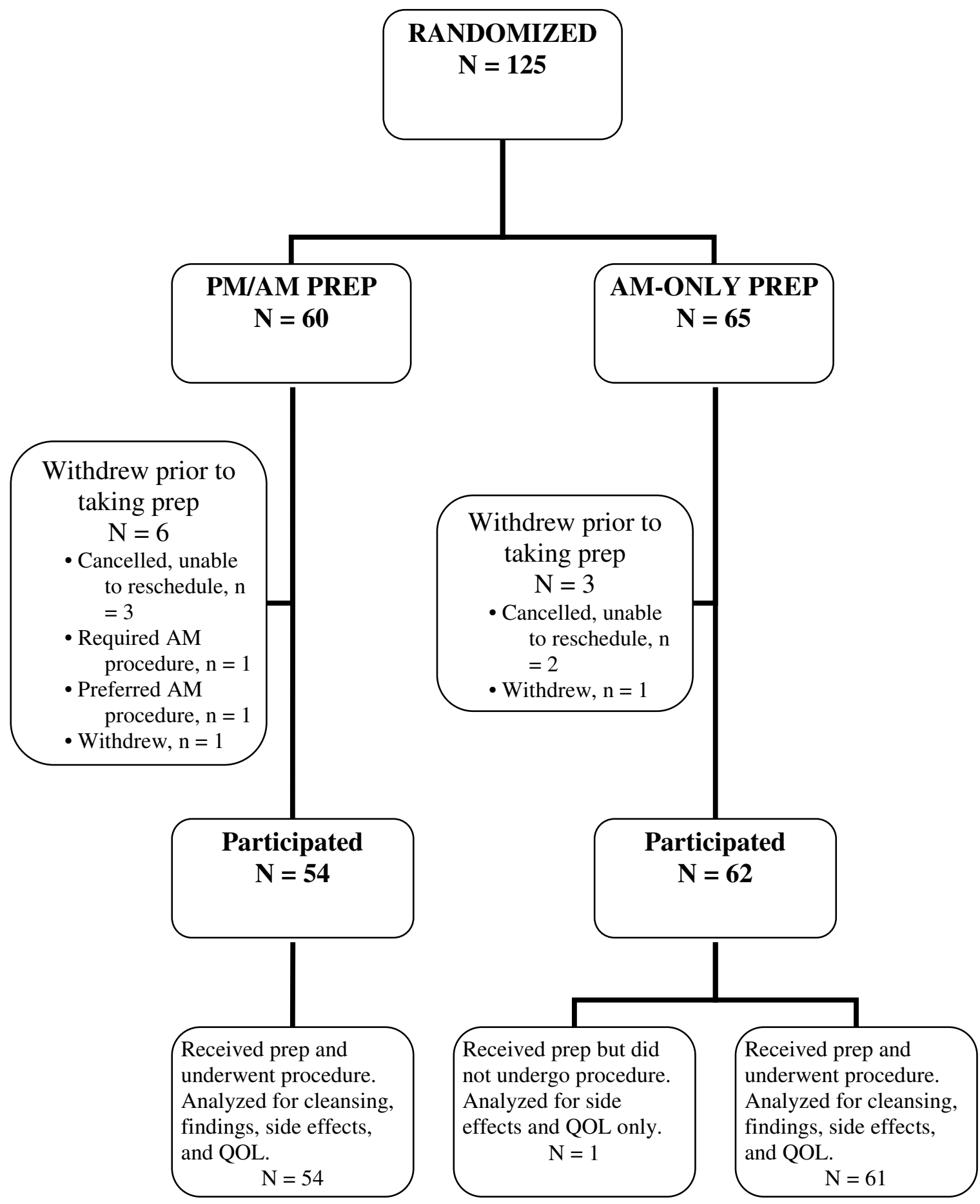


1. Table 1. Summary of assumptions and pre-specified non-inferiority margins for trial endpoints

\begin{tabular}{|l|c|c|}
\hline & $\begin{array}{c}\text { Projected for } \\
\text { PM/AM group }\end{array}$ & $\begin{array}{c}\text { Non-inferiority margin } \\
\text { for AM-only group }\end{array}$ \\
\hline Prep quality adequate (\% patients) & $90 \%$ & $-15 \%$ \\
\hline Flush needed (\% patients) & $50 \%$ & $+25 \%$ \\
\hline Number of polyps per patient (mean) & 1.0 & -0.250 \\
\hline $\begin{array}{l}\text { Number of findings (adenomas or cancer) per } \\
\text { patient (mean) }\end{array}$ & 0.5 & -0.125 \\
\hline Any adenoma or cancer found (\% of patients) & $20-25 \%$ & $-5 \%$ \\
\hline $\begin{array}{l}\text { Any high-risk adenoma or cancer found } \\
(\% \text { patients) }\end{array}$ & $10 \%$ & $-2.5 \%$ \\
\hline
\end{tabular}

2. Table 2. Descriptive summary of characteristics of trial participants $(N=116)$

\begin{tabular}{|l|r|r|r|r|}
\hline & \multicolumn{2}{|c|}{$\begin{array}{r}\text { PM/AM } \\
\text { (N=54) }\end{array}$} & \multicolumn{2}{|c|}{$\begin{array}{c}\text { AM-ONLY } \\
\text { (N=62) }\end{array}$} \\
\hline Age, mean \pm sd & 51 & \pm 13 & 53 & \pm 11 \\
\hline Sex, $\mathrm{n}(\%)$ & & & & \\
\hline Female & 25 & $(46)$ & 38 & $(61)$ \\
Male & 29 & $(54)$ & 24 & $(39)$ \\
\hline Indication, $\mathrm{n}(\%)$ & & & & \\
\hline Screening & 28 & $(52)$ & 31 & $(50)$ \\
Surveillance & 10 & $(19)$ & 10 & $(16)$ \\
Symptoms & 16 & $(30)$ & 21 & $(34)$ \\
\hline First colonoscopy, $\mathrm{n}(\%)$ & 32 & $(59)$ & 29 & $(47)$ \\
\hline Past medical history & & & & \\
\hline Diabetes, $\mathrm{n}(\%)$ & 4 & $(7)$ & 5 & $(8)$ \\
Thyroid disease, $\mathrm{n}(\%)$ & 2 & $(4)$ & 6 & $(10)$ \\
Hypertension, $\mathrm{n}(\%)$ & 18 & $(33)$ & 17 & $(27)$ \\
GERD, $\mathrm{n}(\%)$ & 8 & $(15)$ & 3 & $(5)$ \\
Inflammatory bowel disease, $\mathrm{n}(\%)$ & 3 & $(6)$ & 2 & $(3)$ \\
Pulmonary disease, $\mathrm{n}(\%)$ & 2 & $(4)$ & 3 & $(5)$ \\
Cardiovascular disease, $\mathrm{n}(\%)$ & 17 & $(31)$ & 11 & $(18)$ \\
Psychiatric disease, $\mathrm{n}(\%)$ & 6 & $(11)$ & 4 & $(6)$ \\
\hline Prior surgery (any), $\mathrm{n}(\%)$ & 21 & $(39)$ & 22 & $(35)$ \\
\hline Medications & & & & \\
\hline Antihypertensives, $\mathrm{n}(\%)$ & 18 & $(33)$ & 22 & $(35)$ \\
Cardiac medications, $\mathrm{n}(\%)$ & 16 & $(30)$ & 15 & $(24)$ \\
Acid suppression medications, $\mathrm{n}(\%)$ & 9 & $(17)$ & 4 & $(6)$ \\
Vitamins, herbs, and supplements, $\mathrm{n}(\%)$ & 5 & $(9)$ & 9 & $(15)$ \\
Other medications, $\mathrm{n}(\%)$ & 19 & $(35)$ & 17 & $(27)$ \\
\hline
\end{tabular}


3. Table 3. Measures of prep quality $(\mathrm{N}=115)$

\begin{tabular}{|c|c|c|c|c|c|}
\hline Prep quality: whole colon, $\mathrm{n}(\%)$ & \multicolumn{2}{|c|}{$\begin{array}{c}\mathrm{PM} / \mathrm{AM} \\
(\mathrm{N}=54)\end{array}$} & \multicolumn{2}{|c|}{$\begin{array}{c}\text { AM-ONLY } \\
\left(\mathrm{N}=61^{*}\right)\end{array}$} & $\begin{array}{c}\mathrm{p} \text { (non-inferiority) } \\
0.013\end{array}$ \\
\hline Adequate (excellent/good) & 51 & (94) & 56 & (92) & \\
\hline Inadequate (fair/poor) & 3 & $(6)$ & 5 & $(8)$ & \\
\hline \multicolumn{6}{|l|}{ Prep quality: whole colon, $\mathrm{n}(\%)$} \\
\hline Excellent & 23 & (43) & 25 & (41) & \\
\hline Good & 28 & (52) & 31 & (51) & \\
\hline Fair & 3 & (6) & 1 & (2) & \\
\hline Poor & 0 & & 4 & (7) & \\
\hline Prep quality: right colon, ${ }^{* *} \mathrm{n}(\%)$ & & & & & 0.003 \\
\hline Adequate (excellent/good) & 49 & $(92)$ & 56 & (93) & \\
\hline Inadequate (fair/poor) & 4 & $(8)$ & 4 & $(7)$ & \\
\hline \multicolumn{6}{|l|}{ Prep quality: right colon,* n (\%) } \\
\hline Excellent & 17 & (32) & 29 & (48) & \\
\hline Good & 32 & $(60)$ & 27 & (45) & \\
\hline Fair & 3 & $(6)$ & 3 & (5) & \\
\hline Poor & 1 & $(2)$ & 1 & $(2)$ & \\
\hline Flush needed, n (\%) & & & & & 0.001 \\
\hline None & 26 & (48) & 35 & (57) & \\
\hline Any & 28 & (52) & 26 & (43) & \\
\hline \multicolumn{6}{|l|}{ Flush needed, n (\%) } \\
\hline None & 26 & (48) & 35 & $(57)$ & \\
\hline$<50 \mathrm{ml}$ & 14 & (26) & 13 & (21) & \\
\hline $50-100 \mathrm{ml}$ & 4 & (7) & 8 & (13) & \\
\hline$>100 \mathrm{ml}$ & 10 & (19) & 5 & (8) & \\
\hline
\end{tabular}

(*) Prep quality not assessed for a single patient who did not undergo colonoscopy (**) Data not available for two patients (one in each group) 
4. Table 4. Prep completion, side effects, and quality of life $(\mathrm{N}=116)$

\begin{tabular}{|c|c|c|c|c|c|}
\hline \multirow[b]{2}{*}{ Completion of $>90 \%$ of both doses, $n(\%)$} & \multicolumn{2}{|c|}{$\begin{array}{c}\text { PM/AM } \\
(\mathrm{N}=54)\end{array}$} & \multicolumn{2}{|c|}{$\begin{array}{c}\text { AM-ONLY } \\
(\mathrm{N}=62)\end{array}$} & \multirow{2}{*}{$\begin{array}{c}\mathrm{p} \text { (difference) } \\
0.175\end{array}$} \\
\hline & 39 & (72) & 52 & (84) & \\
\hline Any side effect, $\mathrm{n}(\%)$ & 45 & (82) & 44 & (72) & 0.273 \\
\hline Nausea, n (\%) & 23 & (43) & 24 & (39) & 0.708 \\
\hline Vomiting, n (\%) & 3 & (6) & 6 & (10) & 0.500 \\
\hline Abdominal pain, $\mathrm{n}(\%)$ & 21 & (39) & 12 & (19) & 0.024 \\
\hline Bloating, n (\%) & 35 & (65) & 31 & $(50)$ & 0.134 \\
\hline Light-headedness, n (\%) & 25 & (46) & 18 & (29) & 0.082 \\
\hline Other side effect, n (\%) & 12 & (22) & 7 & (11) & 0.136 \\
\hline Overall satisfaction* (0-10 scale), median [IQR] & 2 & {$[0,5]$} & 4 & {$[1,4]$} & 0.975 \\
\hline Slept for $>\mathbf{8 0} \%$ of usual hours, $\mathrm{n}(\%)$ & 41 & $(76)$ & 44 & $(71)$ & 0.675 \\
\hline Sleep quality, n (\%) & & & & & 0.007 \\
\hline Very good & 1 & (2) & 12 & (19) & \\
\hline Good & 23 & (43) & 13 & (21) & \\
\hline Average & 21 & (39) & 24 & (39) & \\
\hline Poor & 8 & (15) & 11 & (18) & \\
\hline Very poor & 1 & $(2)$ & 2 & $(3)$ & \\
\hline Went to work, $* * \mathrm{n}(\%)$ & 22 & $(56)$ & 27 & $(64)$ & 0.503 \\
\hline Interference with work, ${ }^{* * *} \mathrm{n}(\%)$ & & & & & 0.019 \\
\hline None & 12 & (55) & 23 & (85) & \\
\hline $1-25 \%$ & 6 & (27) & 3 & (11) & \\
\hline $26-50 \%$ & 3 & (14) & 0 & & \\
\hline $51-75 \%$ & 0 & & 1 & (4) & \\
\hline$>75 \%$ & 1 & $(5)$ & 0 & & \\
\hline Interference with overall productivity, $\mathrm{n}(\%)$ & & & & & 0.687 \\
\hline None & 25 & (46) & 34 & (55) & \\
\hline $1-25 \%$ & 18 & (33) & 21 & (34) & \\
\hline $26-50 \%$ & 3 & (6) & 2 & (3) & \\
\hline $51-75 \%$ & 5 & (9) & 4 & (6) & \\
\hline$>75 \%$ & 3 & (6) & 1 & (2) & \\
\hline
\end{tabular}

(*) Likert scale $0=$ highly satisfied, $10=$ highly dissatisfied

(**) Only among patients who routinely work outside the home (39 in PM/AM group and 42 in AM-only group)

(***) Only among patients who went to work (22 in PM/AM group and 27 in AM-only group) 
5. Table 5. Colonoscopy findings $(\mathrm{N}=114)$

\begin{tabular}{|c|c|c|c|c|c|}
\hline \multirow[b]{2}{*}{ Number of polyps $* *$, mean $(\mathrm{sd})$} & \multicolumn{2}{|c|}{$\begin{array}{c}\text { PM/AM } \\
(\mathrm{N}=54)\end{array}$} & \multicolumn{2}{|c|}{$\begin{array}{c}\text { AM-ONLY } \\
\left(\mathrm{N}=60^{*}\right)\end{array}$} & \multirow{2}{*}{$\begin{array}{c}\mathrm{p} \text { (non-inferiority) } \\
0.007\end{array}$} \\
\hline & 0.94 & (1.6) & 1.57 & (2.1) & \\
\hline \multicolumn{6}{|l|}{ Number of polyps**, n (\%) } \\
\hline 0 & 33 & (61) & 27 & (45) & \\
\hline 1 & 9 & (17) & 10 & (17) & \\
\hline 2 & 3 & (6) & 9 & (15) & \\
\hline 3 & 4 & (7) & 4 & (7) & \\
\hline 4 & 3 & (6) & 3 & $(5)$ & \\
\hline $5+$ & 2 & (4) & 7 & (12) & \\
\hline Any polyps detected, n (\%) & 21 & $(39)$ & 33 & $(55)$ & \\
\hline Number of findings $* * *$ per patient, mean $(\mathrm{sd})$ & 0.46 & $(1.0)$ & 0.70 & $(1.3)$ & 0.047 \\
\hline \multicolumn{6}{|l|}{ Number of findings per patient, $\mathrm{n}(\%)$} \\
\hline 0 & 40 & (74) & 38 & (63) & \\
\hline 1 & 7 & (13) & 14 & (23) & \\
\hline 2 & 5 & (9) & 2 & (3) & \\
\hline $3+$ & 2 & (4) & 6 & (10) & \\
\hline \multicolumn{6}{|l|}{ Pathology finding, $\mathrm{n}(\%)$} \\
\hline No polyps, hyperplasia, or benign & 40 & (74) & 38 & (63) & \\
\hline Low-risk adenoma $^{+}$ & 8 & (15) & 14 & (23) & \\
\hline High-risk adenoma $\propto$ & 5 & (9) & 7 & (12) & \\
\hline Cancer & 1 & $(2)$ & 1 & $(2)$ & \\
\hline Any finding***, $\mathrm{n}(\%)$ & 14 & (26) & 22 & (37) & 0.038 \\
\hline High-risk adenoma or cancer, n (\%) & 6 & $(11)$ & 8 & (13) & 0.282 \\
\hline
\end{tabular}

(*) Findings not available for two patients, one who did not undergo colonoscopy and another whose colonoscopy was aborted due to very poor prep

(**) Number of polyps refers to all polyps

$(* * *)$ Finding includes adenoma or cancer

$\left(^{+}\right)$Low-risk includes low-grade dysplasia or serrated adenomas that are $<1 \mathrm{~cm}$

( c) High-risk includes any of the following: villous, high-grade dysplasia, or size $\geq 1 \mathrm{~cm}$

\section{Study Highlights}

\section{What is current knowledge}

- Optimal colon cleansing requires purgative administration close to the time of colonoscopy. Traditionally, split dosing has been used.

- Alternatively, the prep can be taken entirely in the morning

\section{What is new here}

- AM-only prep is as effective as PM/AM prep for achieving adequate colon cleansing for afternoon colonoscopy.

- Patients taking AM-only prep had significantly less abdominal pain, better sleep quality, and less interference with the work day prior. 


\section{References}

1. Rex DK, Johnson DA, Anderson JC et al. American College of Gastroenterology Guidelines for Colorectal Cancer Screening 2009. Am J Gastroenterol 2009;104:739750.

2. Parra-Blanco A, Nicolas-Perez D, Gimeno-Garcia A et al. The timing of bowel preparation before colonoscopy determines the quality of cleansing, and is a significant factor contributing to the detection of flat lesions: A randomized study. World J Gastroenterol 2006;12:161-6.

3. Chiu H-M, Lin J-T, Wang H-P et al. The impact of colon preparation timing on colonoscopic detection of colorectal neoplasms-A prospective endoscopist-blinded randomized trial. Am J Gastroenterol 2006;101:2719-25.

4. Aoun E, Abdul-Baki H, Azar C et al. A randomized single-blind trial of split-dose PEG-electrolyte solution without dietary restriction compared with whole dose PEGelectrolyte solution with dietary restriction for colonoscopy preparation. Gastrintest Endosc 2005;62:213-8.

5. El Sayed AM, Kanafani ZA, Mourad FH et al. A randomized single-blind trial of whole versus split-dose polyethylene glycol-electrolyte solution for colonoscopy preparation. Gastrointest Endosc 2003;58:36-40.

6. Caswell M, Thompson WO, Kanapka JA et al. The time course and effect on serum electrolytes of oral sodium phosphates solution in healthy male and female volunteers. Can J Clin Pharmacol 2007;14:e260-74.

7. Rex DK. Dosing considerations in the use of sodium phosphate bowel preparations for colonoscopy. Ann Pharmacother 2007;41:1466-75. 
8. Church, JM. Effectiveness of polyethylene glycol antegrade gut lavage bowel preparation for colonoscopy-timing is the key! Dis Colon Rectum 1998;41:1223-5.

9. Hakkaart-van Roijen L, Essink-Bot ML. The Health and Labour Questionnaire. Institute for Medical Technology Assessment 2000.

10. Harewood GC, Sharma VK, de Garmo P. Impact of colonoscopy preparation quality on detection of suspected colonic neoplasia. Gastrointest Endosc 2003;58:76-9.

11. Ness RM, Manam R, Hoen H et al. Predictors of inadequate bowel preparation for colonoscopy. Am J Gastroenterol 2001;96:1797-1802.

12. Hsu C-W, Imperiale TF. Meta-analysis and cost comparison of polyethylene glycol lavage versus sodium phosphate for colonoscopy preparation. Gastrointest Endosc $1998 ; 48: 276-82$.

13. Tan JJ, Tjandra JJ. Which is the optimal bowel preparation for colonoscopy - a metaanalysis. Colorectal Dis 2006;8:247-58.

14. DiPalma JA, Wolff BG, Meagher A et al. Comparison of reduced volume versus four liters sulfate-free electrolyte lavage solutions for colonoscopy colon cleansing. Am J Gastroenterol 2003;98:2187-91.

15. Ell C, Fischbach W, Bronisch H-J et al. Randomized trial of low-volume PEG solution versus standard PEG + electrolytes for bowel cleansing before colonoscopy. Am J Gastroenterol 2007;102:1-11.

16. Abuksis G, Mor M, Segal N et al. A patient education program is cost-effective for preventing failure of endoscopic procedures in a gastroenterology department. Am J Gastroenterol. 2001;96:1786-1790. 
17. Reilly T, Walker G. Reasons for poor colonic preparation for inpatients. Gastroenterol Nurs 2004;27:115-7.

18. Adams WJ, Meagher AP, Lubowski DZ et al. Bisacodyl reduces the volume of polyethylene glycol solution required for bowel preparation. Dis Colon Rectum 1994;37:229-34.

19. Rex DK, Overley C, Kinser K et al. Safety of propofol administered by registered nurses with gastroenterologist supervision in 2000 endoscopic cases. Am J Gastroenterol 2002;97:1159-63.

20. Olsson GL, Hallen B, Hambraeus-Jonzon K. Aspiration during anaesthesia: A computer-aided study of 185,358 anaesthetics. Acta Anaesthesiol Scand 1986;30:8492.

21. Warner M, Warner M, Weber J. Clinical significance of pulmonary aspiration during the perioperative period. Anesthesiology 1993;78:56-62.

\section{Conflict of Interest/Study Support}

Guarantor of the article: David Kastenberg, M.D.

Specific author contributions: The authors' responsibilities were as follows: D.K. had full access to all the data in the study and takes responsibility for the integrity of the data and the accuracy of the data analyses. D.K., C.D.: study concept and design; D.K., L.K: contributed patients to the study and performed the study colonoscopies; R.M., A.S., M.S., A.M.: randomization assignment, patient consent and instructions, distribution of MoviPrep®, data collection; C.D.: data analyses and interpretation; R.M., D.K., C.D.: drafting and revision of manuscript. All authors approved the final draft for submission. 
Financial support: Salix Pharmaceuticals, Inc. funded this study and provided MoviPrep® for all patients. The sponsor of this study had no role in study design, data collection, data analysis, data interpretation, or writing of the report.

Potential competing interests: D.K is a speaker and consultant for and receives research support from Salix Pharmaceuticals, Inc. 